\title{
Interactions between fishing strategies of nephrops trawlers in the Bay of Biscay and Norway lobster diel activity patterns
}

\author{
V. M. Trenkel ${ }^{\star}$, M.-J. Rochet \& S. Mahévas
}

Département Ecologie et Modèles pour l'Halieutique, IFREMER, Nantes, France.

* : Corresponding author: Verena Trenkel, Département EMH, rue de l'île d'Yeu, B.P. 21105, 44311 Nantes cedex 3, France. Tel+ 33 240374000; fax: + 33 240374075; verena.trenkel@ifremer.fr.

\begin{abstract}
:
Norway lobster, Nephrops norvegicus (L.) was found to show diel activity patterns with more individuals outside their burrows at dawn and dusk in the Bay of Biscay in August 2004 and catchabilities were higher at these times. Using data from an onboard observer programme of Nephrops trawlers in 2002-2005, we investigated whether the expected variability in catchability was visible in commercial catches. Catch numbers per haul varied spatially and between months but no signal for diel variations was found. Fishing strategies developed by the Nephrops trawlers had several components. On a seasonal level they started around sunrise. On a haul level, haul duration decreased from haul to haul, with the longest hauls taking place at the time of highest catchability. The by-catch of hake, Merluccius merluccius (L.) increased more than proportionally with haul duration.
\end{abstract}

Keywords: catchability, diel activity patterns, fishing strategy, time of day 


\section{Introduction}

Trawl catchability of fish and shellfish has important consequences for the interpretation of catch data collected during scientific surveys as well as for the yield of commercial fishing operations. Trawl catchability is commonly broken down into gear efficiency (including selectivity) and horizontal and vertical availability (see overview by Godø 1994a). Horizontal availability is the probability that an individual is found in the swept area while vertical availability is the probability that an individual is at the right distance from the sea floor in order to be caught by the fishing gear. Gear efficiency is the result of fish behaviour (avoidance or herding), mesh selectivity and different factors related to gear rigging and fishing vessel characteristics (e.g. engine power or crew experience). Seasonal variations in catchability are generally the result of changes in horizontal availability as populations gather for spawning and disperse thereafter. Short term environmental conditions, such as water currents or sea state, can affect both the fishing gear and animal behaviour and hence affect all three catchability components on an irregular basis (Engås 1994). Tidal and day-night changes lead to regular variations, mainly in vertical availability (Godø 1994b, Michalsen, Godø \& Fernö 1996). Differences between day and night catches have been reported from many areas for a variety of species (e.g. Casey \& Myers 1998, Korsbrekke \& Nakken 1999, Benoît \& Swain 2003).

To avoid the effect of diel variations in availability on survey catches, scientific surveys are often constrained to day-light hours although attempts have been made to correct for diel variations (Hjellvik, Godø \& Tjøstheim 2002, Benoît \& Swain 2003). Commercial catches should equally be affected by diel variations. However, little is known about the fishing strategies developed in response to these variations on various temporal scales, from the haul to the seasonal level. Most studies of fishing strategies have concentrated on the intermediate fishing trip level (e.g. Holland \& Sutinen 2000, Pelletier \& Ferraris 2000).

The northern part of the continental shelf of the Bay of Biscay (north-eastern Atlantic) is covered by a sedimentary bank known as the Grande Vasière. It is home to a commercially exploited Nephrops norvegicus population, but also an important habitat for hake, Merluccius merluccius (L.) (Le Danois 1920). Juvenile hake and Nephrops are taken as bycatch in the Nephrops bottom trawl fishery, leading to high levels of discards (M.J. Rochet, pers. com.), similar to those observed in Nephrops fisheries elsewhere (e.g. Stratoudakis, Fryer, Cooke, Pierce \& Coull 2001). In 2003 this Nephrops fishery comprised 278 vessels (Leblond, Daurès, Berthou, Bermell, Merrien \& Demaneche 2005). About half also fished for other species at some point during the year. Seasonal variations of target species (Poulard \& Léauté 2002) and fishing areas (Léauté 1998) are thought to compensate for variations in availability and accessibility of the target species Nephrops.

In many areas Nephrops have a pronounced diel activity pattern, with emergence at sunset and return to the burrows at dawn, and little activity during the day (e.g. Chapman \& Howard 1979; Chapman 1980). Trenkel, Le Loc'h \& Rochet (2007) found similar patterns in the Bay of Biscay in a video study carried out in August 2004. The diel patterns seem to be modified by depth, although this cannot be directly explained by light levels (Aguzzi, Sardà, Abelló, Company \& Rotllant 2003). Nephrops activity also varies on a seasonal basis. In the Bay of Biscay, Nephrops females retreat to their burrows in about November and emerge from February onwards for larvae hatching (Fontaine \& Warluzel 1969).

The diel and seasonal activity patterns of Nephrops are expected to influence its catchability by commercial trawling, but few studies have investigated the factors influencing commercial Nephrops catches. Maynou \& Sardà (2001) found that deep-water (200-650 m) Nephrops catches were explained by depth, atmospheric pressure, sea state and cloud cover (they did not study diel patterns). Poulard \& Léauté (2002) explained seasonal variations in Ipue (landings per unit effort) by burrowing activity patterns. Diel variations in commercial catches and thus catchability do not seem to have been investigated. In this paper the strategic response of the Bay of Biscay Nephrops fleet to the variations in availability of Nephrops on a diel and seasonal level were examined and compared with patterns obtained from a scientific trawl survey. 


\section{Material and Methods}

\section{Scientific survey}

To explore diel patterns in catches undisturbed by variations in vessel performance, catch and video (see Trenkel et al. 2007) data were collected in July 2004 in a restricted area in the Northern part of the Grande Vasière at depths of around $100 \mathrm{~m}$ (Fig. 1). Thirty five, onehour hauls at 3.5 knots were carried out with a hired Nephrops trawler, equipped with ScanTrawl instruments for monitoring trawl geometry. Trawl sampling was evenly spread between early morning and mid afternoon and across five closely located areas. All catch was sorted and measured.

\section{On board commercial catch sampling}

Haul level data from on board sampling of commercial catches of trawlers targeting Nephrops in the Bay of Biscay was available for the period 2002 to 2005 with 20, 34, 38 and 33 fishing trips sampled respectively. The duration of sampled trips was mainly one day, in which case the last haul of the day was not sampled as there was no time before returning to the harbour. Sampling was spread about evenly across months in all years, except 2002 when sampling started in July, and covered vessels registered in different ports. The sampling fraction of all Nephrops trips was around $0.2 \%$ in 2004 and 2005. For each haul, a standard basket of catch was sorted into discards and landings. A sample was then taken from the discards, sorted and lengths measured, while the sorted landings were added to the remaining landings. All landings were weighted by species and measured. Total catch per haul were estimated as the sum of landings and estimated discards (landings times discard ratio in the sorted basket). The data consisted of the estimated total catch by species, plus explanatory information on depth, time and duration of each haul. A variable for the time difference between sunrise and the beginning of each haul was created. For this relative starting time variable, the time of sunrise at day 15 in each month was subtracted from the actual time.

Hauls carried out in three neighbouring statistical rectangles, 23E5, 23E6 and 24E5, were selected from the onboard sampling data base (Fig. 1). These three rectangles correspond to the northern part of the Grande Vasière and include the area surveyed in 2004. The main study object was Nephrops, but hake catches were also analysed.

\section{Data analysis}

Diel patterns in survey catches

Generalised additive models (GAM) were used for modelling Nephrops and hake survey catch numbers as smooth functions of time of the day, s(time), swept area, s(swept area) and study area using a negative binomial error distribution with a log-link function:

$$
\text { number }=s(\text { time })+s(\text { swept area })+\text { area }
$$

The appropriate error distribution and link function were selected based on visual inspection of residual plots. Model fitting and automatic selection of the degrees of freedom (df) for the thin plate regression splines s(.), were performed using the mgcv package in $R(R$ development Core Team 2003). For all models, the adjusted $R^{2}$ value was used for judging goodness-of-fit.

Fishing strategy

To investigate fishing strategies, haul duration and haul depth were modelled as a linear function of haul rank (order number of the haul during the fishing trip) and a smooth nonparametric function of month, $s$ (month). Rectangle and year were added as categorical variables to account for any spatial and interannual variability. As the distribution of haul depth measurements was left-skewed, depth was transformed as maximum depth (140 m) minus depth to make the distribution right-skewed, which is easier to handle by a parametric distribution. Thus, the following models were fitted

$$
\begin{aligned}
& (\text { 140-depth })=s(\text { month })+\text { rank }+ \text { rectangle }+ \text { year } \\
& \text { duration }=s(\text { month })+\text { rank }+ \text { rectangle }+ \text { year }
\end{aligned}
$$


For haul duration a Gaussian error distribution was chosen and the same for (140-depth) but with a log-link function to take account of skewness.

To explore the relative effects of fishing strategies and other covariables on catches, catch numbers per haul for Nephrops and hake were modelled in a similar manner as described above, but adding haul duration and depth to the list of covariables. Instead of haul rank, the starting time in hours before sunrise (relTime) was used. The fitted model was

numbers $=$ offset(log (duration $))+$ te $(\log ($ duration $)$, relTime $)+$ depth + rectangle + month + year

Month and year were treated as factors and haul duration as an offset, i.e. with the slope fixed at 1 , because doubling the duration can be expected to double the catch. Again a negative binomial distribution with a log-link function was chosen to represent the overdispersion in catch numbers. Haul duration was also log-transformed because of the log-link function. te() indicates a two-dimensional smooth function fitted using tensor products with thin plate regression splines for both covariates; for Nephrops a separate term was fitted for summer (May to August) and the remainder of the year, e.g. te(log(duration), relTime): summer).

Mean length in the catch was modelled in a similar manner as catch numbers but using a Gaussian error distribution. Note that haul duration was not log-transformed in this case as the identity link-function was used.

mean length $=\mathrm{te}($ duration, relTime $)+$ rectangle + month + year

Finally discard rates in numbers (discards/catch) were investigated with a quasi-binomial error distribution and a log-link function. Mean length was added to the list of explanatory variables used above.

\section{Results}

\section{Diel patterns in survey data}

Nephrops but not hake numbers caught varied significantly at small spatial scales $(P=$ 0.005 and $P=0.086$ respectively for area effect). Swept area $(P=0.26$ and $P=0.35$ respectively) did not explain any variability for either species which is not surprising given haul duration was standardised and hence swept area varied little. Nephrops numbers per haul decreased regularly $(P<0.001)$ from sunrise to mid-day (Fig. 2). For Nephrops the adjusted $R^{2}$ of the fitted model was 0.59 while for hake it was only 0.21 .

\section{Fishing strategies}

The Nephrops trawlers in the Bay of Biscay adapted their fishing activity to the time of sunrise. While the time of the first haul (median) differed by around two hours between summer and winter (Fig. 3a), the difference with respect to the time of sunrise was much smaller, with most fishing days starting between 0.5-1 hour before sunrise irrespective of the month (Fig. 3b).

The average depth of sampled fishing hauls was around $110 \mathrm{~m}$ (Fig. 3c), with the exception of January and February where they were slightly shallower. The GAM model fitted to haul depth (transformed as 140-depth) was significant for month (s(month), $P=$ $0.0002)$, rectangle $(P<0.001)$ and year $(P=0.006)$ but not for haul rank $(P=0.50)$; the adjusted $R^{2}$ for the model was 0.21 . This suggests that fishing was carried out in slightly shallower areas closer to the coast at the beginning of the year and also agrees with earlier relative start times (more than one hour before sunrise in January) at this period of the year as closer to the coast means less travel time.

Haul duration was linked to the rank of a haul (Fig. 3d). The GAM model confirmed that rank was a significant explanatory variable $(P<0.001)$ and also rectangle $(P<0.001)$, but not month $(P=0.53)$ or year $(P=0.29)$. This model explained only a small proportion of haul duration variability (adjusted $R^{2}=0.27$ ). Successive hauls in a day became shorter, from an average duration of $2.9 \mathrm{~h}$ for the first haul, $2.6 \mathrm{~h}$ for the second and $2 \mathrm{~h}$ for the third and decreased slightly with depth. Haul duration was measured between the moment the trawl reached the bottom to when it started to lift. 


\section{Catch composition}

The number of Nephrops caught per haul did not differ between the three statistical rectangles considered in this analysis (Table 1 ). It only depended on year, but neither on month or depth nor on the starting time of the haul (nonparametric relationship); for the later variable in neither summer or winter months. The model explained only a small part of the observed variability (adjusted $\mathrm{R}^{2}=0.12$ ), thus random interhaul variability dominated Nephrops catches.

For hake, there was a significant difference between months and rectangles in the number of hake in the catch but not for years or depth (Tab. 1). Catch numbers (log-scale) were explained by the two-dimensional relationship with haul duration and relative starting time (Fig. 4a). As the contour lines were rather parallel in Fig. 4a, this indicates that there was no interaction between haul duration and starting time. Hence separate relationships were also fitted (Figs. 4b\&c). They confirm a linear relationship with haul duration (slope 1.12, S.D. 0.3; $P<0.001$ ) and a non-significant linear relationship with relative starting time $(P=0.24)$. Note that the relationship with haul duration is in addition to the linear relationship implemented through the offset. Thus, hake numbers were not directly related to haul duration but were larger for longer hauls.

Mean length of Nephrops in catches varied significantly between months $(P<0.001)$ and years $(P<0.001)$, but did not change with rectangle $(P=0.41)$. A significant effect of the interaction term of haul duration and starting time was found $(P<0.001)$ which was due to smaller mean length for longer hauls (slope -1.17, S.D. 0.29), but not starting time $(P=$ 0.14). By contrast, for hake mean length in the catch did not change with months $(P=0.11)$, but significant differences were found between rectangles $(P=0.02)$ and years $(P<0.001)$ and there was a decrease in mean length with depth (slope -0.07, S.D. $0.02, P<0.001$ ). Haul duration and starting time did not have any impact on mean length of hake $(P=0.20)$. For both species the models only explained a small proportion of the observed variability (adjusted $\mathrm{R}^{2} 0.33$ for Nephrops and 0.24 for hake)

\section{Discarding}

Nephrops discard rates (numbers discarded/caught) significantly increased through the years $(P<0.001)$ and varied between months $(P=0.002)$, but did not change with depth $(P$ $=0.62)$ or rectangle $(P=0.05)$. No effect of haul duration or relative starting time on Nephrops discard rates was found in winter $(P=0.15)$, but there was some indication that discard rates were higher for longer hauls during the summer $(P=0.02$; Fig. 5). Discard rates strongly decreased with increasing mean length in the catch $(P<0.001)$. Overall the model provided a good description of the variability in discard rates (adjusted $R^{2}=0.72$ ) .

\section{Discussion}

This study demonstrates that Nephrops fishers in the Bay of Biscay have adapted their fishing strategy to the biology of their target species by varying the starting time of fishing during the year to make it constant with respect to the time of sunrise and by carrying out longer hauls early in the morning. An unwanted side effect of varying haul duration was that average Nephrops size decreased as haul duration increased. A possible explanation for this observation is that as the net fills up in longer hauls, the mesh become obstructed and undersized Nephrops are no longer able to escape.

No diel patterns were found in Nephrops commercial catches, neither during the summer months nor during the rest of the year. By contrast, catch numbers in scientific hauls showed the expected decrease from sunrise onwards. One possible explanation is related to the onboard sampling protocol interacting with the fishing strategy. One standard basket was always sorted into discards and landings independent of total catch size. A subsample of the discards fraction was sorted by species while all landings were sorted. Total discards by species was then estimated by multiplying total landings by the discard ratio in the sorted basket. Total catch is then the sum of estimated total discards and total landings. If the sorting pattern of Nephrops fishers retained larger or fewer individuals in bigger catches, i.e. they apply a selection ogive shifted to the right or simply retain fewer individuals, this might not be visible in the data as the fisher sorting the sampling basket always sorted the same amount corresponding to a small catch, thus retaining more individuals compared with the remainder of the catch. In that case, the estimated discard ratio would be underestimated 
and as a consequence, also total catch. Although this is speculative, there was some evidence that discard rates were higher for longer hauls, which would support the hypothesis of sorting practices depending on total catch, which in turn is a result of haul duration. Further evidence for this hypothesis comes from analysis of Nephrops landings which should be correctly estimated by the implemented sampling protocol. No time of day effect was found for Nephrops landings (results not shown). Thus it seems most likely that fishing strategies retained fewer individuals from hauls carried out earlier in the morning, which would mean that fishers were not benefiting from increased availability of Nephrops. The above considerations show that the adopted sampling protocol might lead to biased catch and discards estimates. However, the protocol did not allow examination of the impact of catch size on selection ogives or variations in discard rates.

Although diel variability in commercial catch rates have been demonstrated for several demersal fish species, e.g. silvery hake (Gillis 1999), characteristics of local fishing strategies that might indicate adaptations to these patterns have not been reported. This study is the first to provide evidence of adaptations of the time of day of fishing, haul duration and possibly sorting practices, while many more studies have been directed at studying spatial fishing strategies, e.g. Hilborn \& Ledbetter (1979), Gillis, Peterman \& Tyler (1993) and Holland \& Sutinen (1999).

In terms of hake catches, there was some weak evidence that hake might be less available to a bottom trawl before/around sunrise. This confirms the findings by Trenkel et al. (2007) based on video observations in the same area. Variation in haul duration detected an increasing catchability of hake with duration. Little is known about the catchability of hake, but it has been observed swimming in front of a bottom trawl (Walsh \& Hickey 1993) and to escape through the near bottom parts of the side panels at the trawl entrance (Dremière, Fiorentini, Cosimi, Leonori, Sala \& Spagnolo 1999). Thus it might be hypothesised that longer hauls tire the hake swimming ahead of the trawl and thus increase its catchability.

It has been argued that fisheries management should account for chronobiological effects in exploited species (Naylor 2005). Nephrops norvegicus is a good example for such effects. Reducing fishing effort during periods of higher catchability would be one way of incorporating Nephrops chronobiology into management. In the absence of management regulations related to the diel or seasonal activity pattern of Nephrops, fishermen have adapted their fishing strategies to maximise their catches, although possibly they don't draw the maximum benefit from it. Furthermore, regulating haul duration might eventually help to reduce discards, but given the current state of knowledge, gear modifications such as selectivity grids tested by Loaec, Morandeau, Meillat \& Davies (2006) or square mesh escape panels (Armstrong, Briggs \& Rihan 1998) are a more direct way of increasing gear selectivity.

\section{Acknowledgement}

We would like to thank our colleagues for carrying out the onboard sampling which was supported under the European Data Collection Regulation scheme. The study received financial support from the European funding scheme IFOP. 


\section{References}

Aguzzi J., Sardà F., Abelló P., Company J.B. \& Rotllant G. (2003) Diel and seasonal patterns of Nephrops norvegicus (Decapoda: Nephropidae) catchability in the western Mediterranean. Marine Ecology Progress Series 258, 201-211.

Armstrong, M.J., Briggs, R.P. \& Rihan, D. (1998) A study of optimum positioning of squaremesh escape panesl in Irish Sea Nephrops trawls. Fisheries Research 43, 179-189.

Benoît H.P. \& Swain D.P. (2003) Accounting for length- and depth-dependent diel variation in catchability of fish and invertebrates in an annual bottom-trawl survey. ICES Journal of Marine Science 60, 1298-1317.

Casey J.M. \& Myers R.A. (1998) Diel variations in trawl catchability: is it as clear as day and night? Canadian Journal of Fisheries and Aquatic Sciences 55, 2329-2340.

Chapman C.J. (1980) Ecology of juvenile and adult Nephrops. In: J Cobb \& B Phillips (eds.) The biology and management of lobsters Vol. II, Academia Press, Inc. II, pp. 143-178.

Chapman C.J. \& Howard F.G. (1979) Field observations on the emergence rhythm of the Norway lobster Nephrops norvegicus, using different methods. Marine Biology 51, 157165.

Dremière P.Y., Fiorentini L., Cosimi G., Leonori I., Sala A. \& Spagnolo A. (1999) Escapement from the main body of the bottom trawl used for the Mediterranean international trawl survey (MEDITS). Aquatic Living Resources 12, 207-217.

Engås A. (1994) The effects of trawl performance and fish behaviour on the catching efficiency of demersal sampling trawls. In: A. Fernö \& S. Olsen Marine Fish Behaviour in Capture and Abundance Estimation. Oxford, Fishing News Books, pp. 45-68.

Fontaine B. \& Warluzel N. (1969) Biologie de la langoustine du golfe de Gascogne Nephrops norvegicus (L.). Revue des Travaux de l'Institut des Pêches maritimes 33: 223-246.

Gillis D.M. (1999) Behavioral inferences from regulatory observer data: catch rate variation in the Scotian Shelf silver hake (Merluccius bilinearis) fishery. Canadian Journal of Fisheries and Aquatic Sciences 56, 288-296.

Gillis D.M., Peterman R.M. \& Tyler A.V. (1993) Movement dynamics in a fishery: application of the ideal free distribution to spatial allocation of effort. Canadian Journal of Fisheries and Aquatic Sciences 50 323-333.

Godø O.R. (1994a) Factors affecting the reliability of groundfish abundance estimates from bottom trawl surveys. In: A. Fernö \& S. Olsen Marine Fish Behaviour in Capture and Abundance Estimation. Oxford, Fishing News Books, pp. 166-197.

Godø O.R. (1994b) Natural fish behaviour and catchability of groundfish. ICES Annual Science Conference. ICES C.M. 1994/G:14.

Godø O.R., Pennington M. \& Vølstad J.H. (1990). Effect of tow duration on length composition of trawl catches. Fisheries Research 9, 165-179.

Hilborn R. \& Ledbetter M. (1979) Analysis of the British Columbia salmon purse-seine fleet: Dynamics of movement. Journal of the Fisheries Research Board Canada 36, 384-391.

Hjellvik V., Godø O.R. \& Tjøstheim D. (2002) Diurnal variation in bottom trawl survey catches: does it pay to adjust? Canadian Journal of Fisheries and Aquatic Sciences 59, 33-48.

Holland D.S. \& Sutinen J. (1999) An empirical model of fleet dynamics in New England trawl fisheries. Canadian Journal of Fisheries and Aquatic Sciences 56, 253-264.

Holland D.S. \& Sutinen J.G. (2000) Location choice in New England trawl fisheries: old habits die hard. Land Economics 76, 133-149.

Korsbrekke K. \& Nakken O. (1999) Length and species-dependent diurnal variation of catch rates in the Norwegian Barents Sea bottom-trawl surveys. ICES Journal of Marine Science 56, 284-291.

Léauté J.-P. (1998) Les flotilles de pêche de l'Union Européenne dans le golfe de Gascogne vues du ciel. Oceanologica Acta 21, 371-381.

Leblond, E., Daurès, F., Berthou, P., Bermell, S., Merrien, C. \& Demaneche, S. (2005) Synthèse des flottilles de pêche 2003. Brest, Ifremer, 54 pp.

Le Danois E. (1920) Le merlu. Office Scientifique et Technique des Pêches Maritimes 2, 132.

Loaec H., Morandeau H., Meillat M. \& Davies P. (2006). Engineering development of flexible selectivity grids for Nephrops. Fisheries Research 79, 210-218. 
Maynou F. \& Sardà F. (2001) Influence of environmental factors on commercial trawl catches of Nephrops norvegicus (L.). ICES Journal of Marine Science 58, 1318-1325.

Michalsen K., Godø O.R. \& Fernö A. (1996) Diel variation in the catchability of gadoids and its influence on the reliability of abundance indices. ICES Journal of Marine Science 53, 389-395.

Naylor E. (2005) Chronobiology: implications for marine resource exploitation and management. Scientia Marina 69 (Suppl. 1), 157-167.

Pelletier D.P. \& Ferraris J. (2000) A multivariate approach for defining fishing strategies form commercial catch and effort data. Canadian Journal of Fisheries and Aquatic Sciences 57, 51-65.

Poulard J.-C. \& Léauté J.-P. (2002) Interaction between marine populations and fishing activites: temporal patterns of landings of La Rochelle trawlers in the Bay of Biscay. Aquatic Living Resources 15, 197-210.

Stratoudakis Y., Fryer R.J., Cooke R., Pierce G.J. \& Coull K.A. (2001) Fish bycatch and discarding in Nephrops trawlers in the Firth of Clyde (west of Scotland). Aquatic Living Resources 14, 283-291.

Trenkel V.M., Le Loc'h F. \& Rochet M.-J. (2007) Small-scale spatial and temporal interactions among benthic crustaceans and one fish species in the Bay of Biscay, Marine Biology 151, 2207-2215.

Walsh S.J. \& Hickey W.M. (1993) Behavioural reactions of demersal fish to bottom trawls at various light conditions. ICES Journal of Marine Science 196, 68-76. 
Table 1. P-values of explanatory variables in GAM model fitted to catch numbers per haul for Nephrops trawler fleet in Bay of Biscay.

winter: September-April; summer: May-August.

\begin{tabular}{lcc}
\hline Variable & N. norvegicus & M. merluccius \\
\hline Depth & 0.12 & 0.27 \\
Rectangle & 0.87 & $<0.001$ \\
Month & 0.09 & $<0.001$ \\
Year & $<0.001$ & 0.17 \\
te(logduration, relTime) & winter 0.67 & 0.0095
\end{tabular}




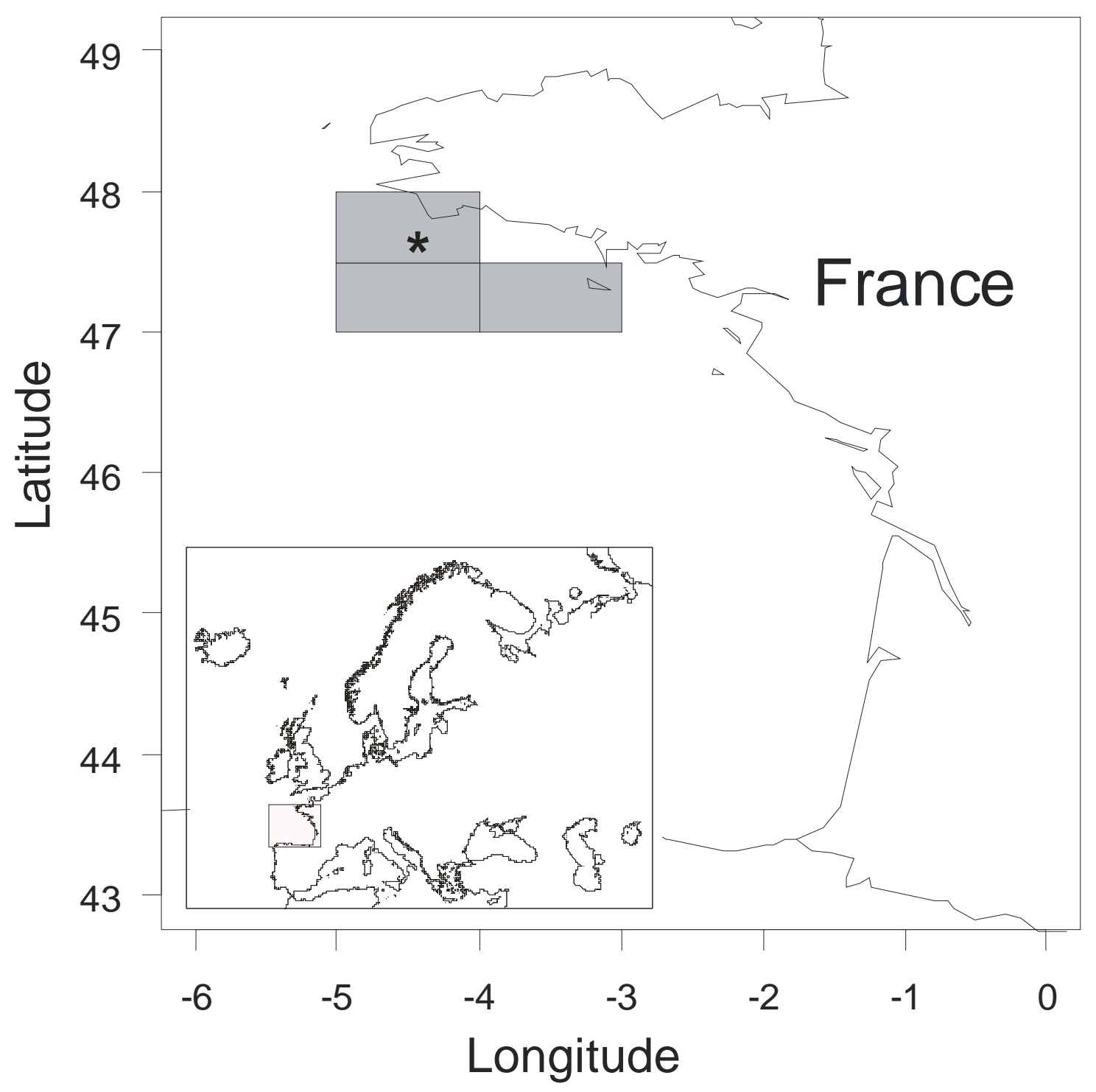

Figure 1. Map of selected statistical rectangles for onboard sampling. Star indicates location of scientific survey. 


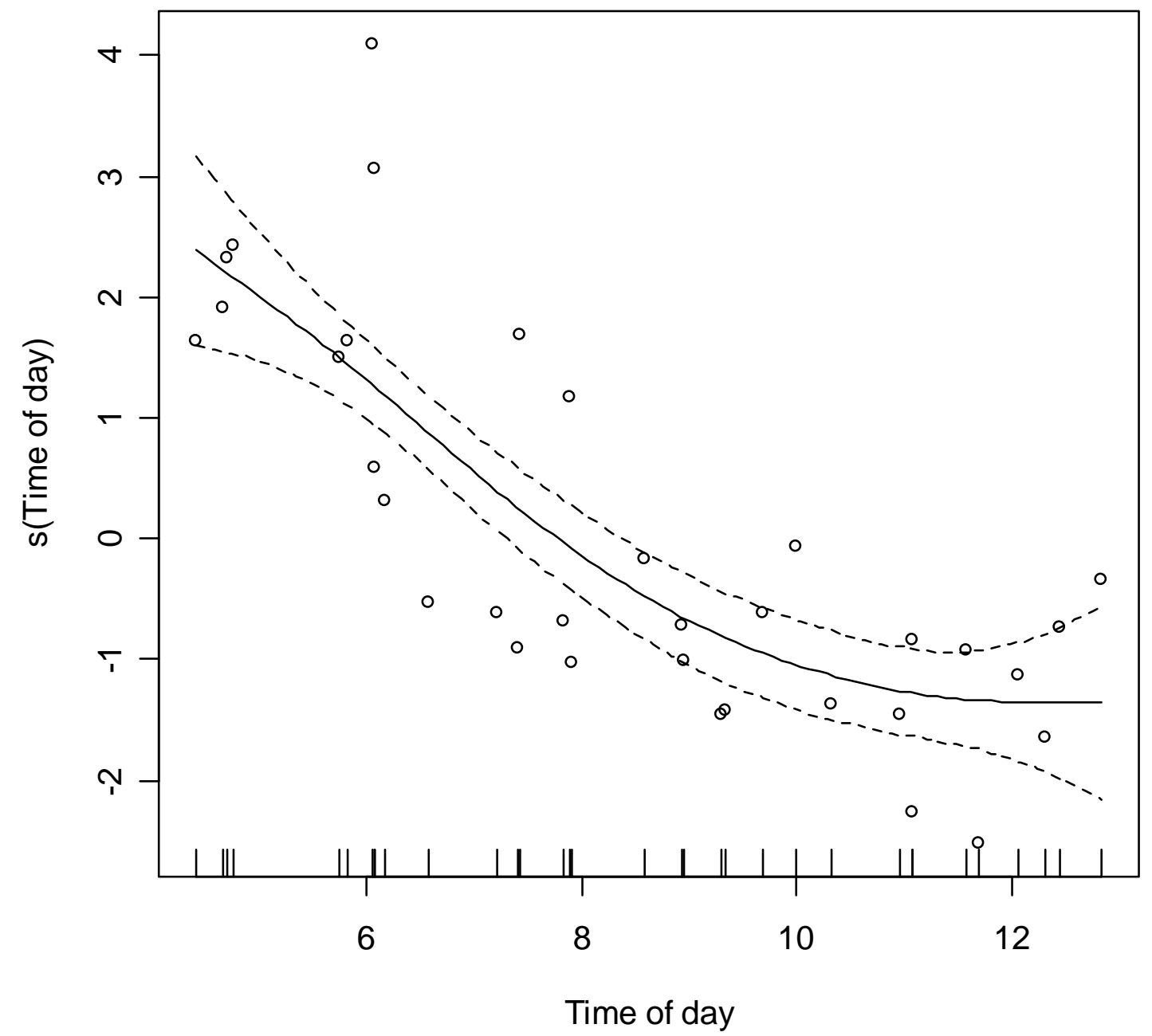

Fig. 2 Mono-variate nonparametric relationship of Nephrops survey catch numbers with haul starting time estimated using a Gam model. Partial residuals and times with data are shown. 

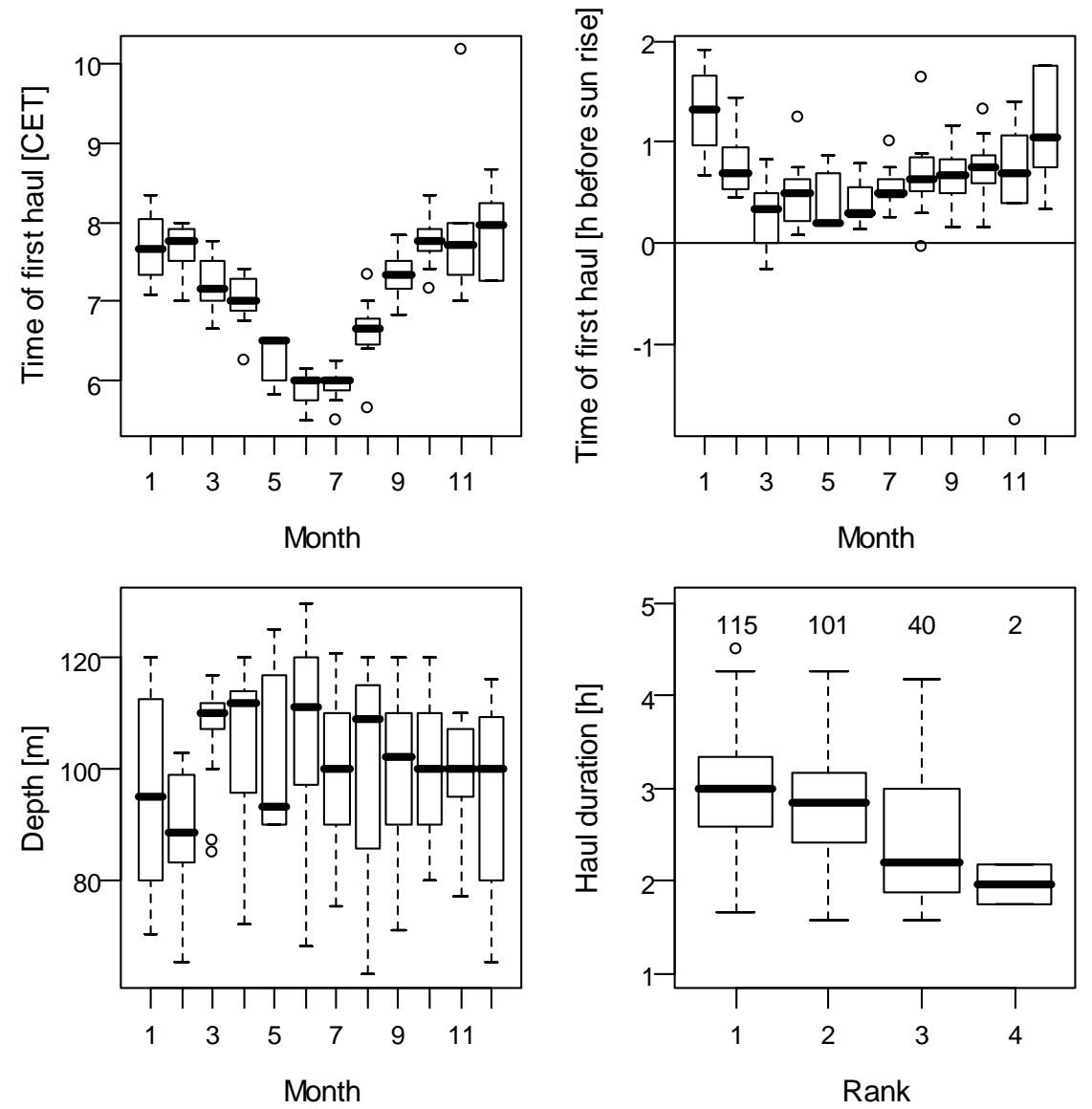

Fig. 3 Boxplots for fishing activity descriptors of a sample of Nephrops trawlers in the Bay of Biscay (2004-2005). a) Central European time (CET) of first haul in the morning; b) Hours before sunrise of first haul, horizontal line indicates sunrise; c) Depth range of hauls by month; d) Haul duration by rank, rank 1 corresponds to first haul in the morning, numbers at top indicate sample size. Boxes indicate interquartile ranges, thick lines are medians with the whiskers being their 95\% confidence intervals and circles giving extreme values outside this confidence interval. 
a)
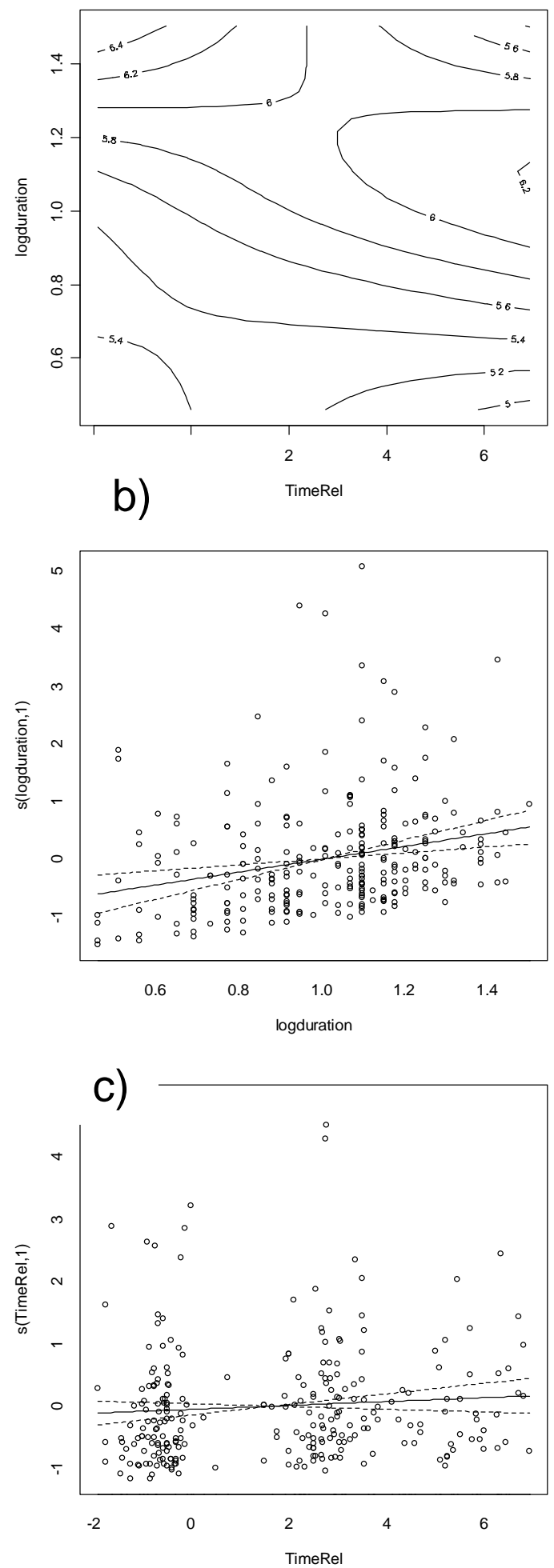

Fig. 4 Estimated coefficients for haul duration and relative starting time in GAM model for the number of hake caught per haul by Nephrops trawlers in the Bay of Biscay. a) Contour plot for predicted catch numbers (log-scale) in July at $100 \mathrm{~m}$; b) mono-variate relationship with log-transformed haul duration; c) mono-variate relationship with relative starting time. Partial residuals are indicated in b) \& c); the confidence intervals join up in the centre due to a model fitting constraint. 


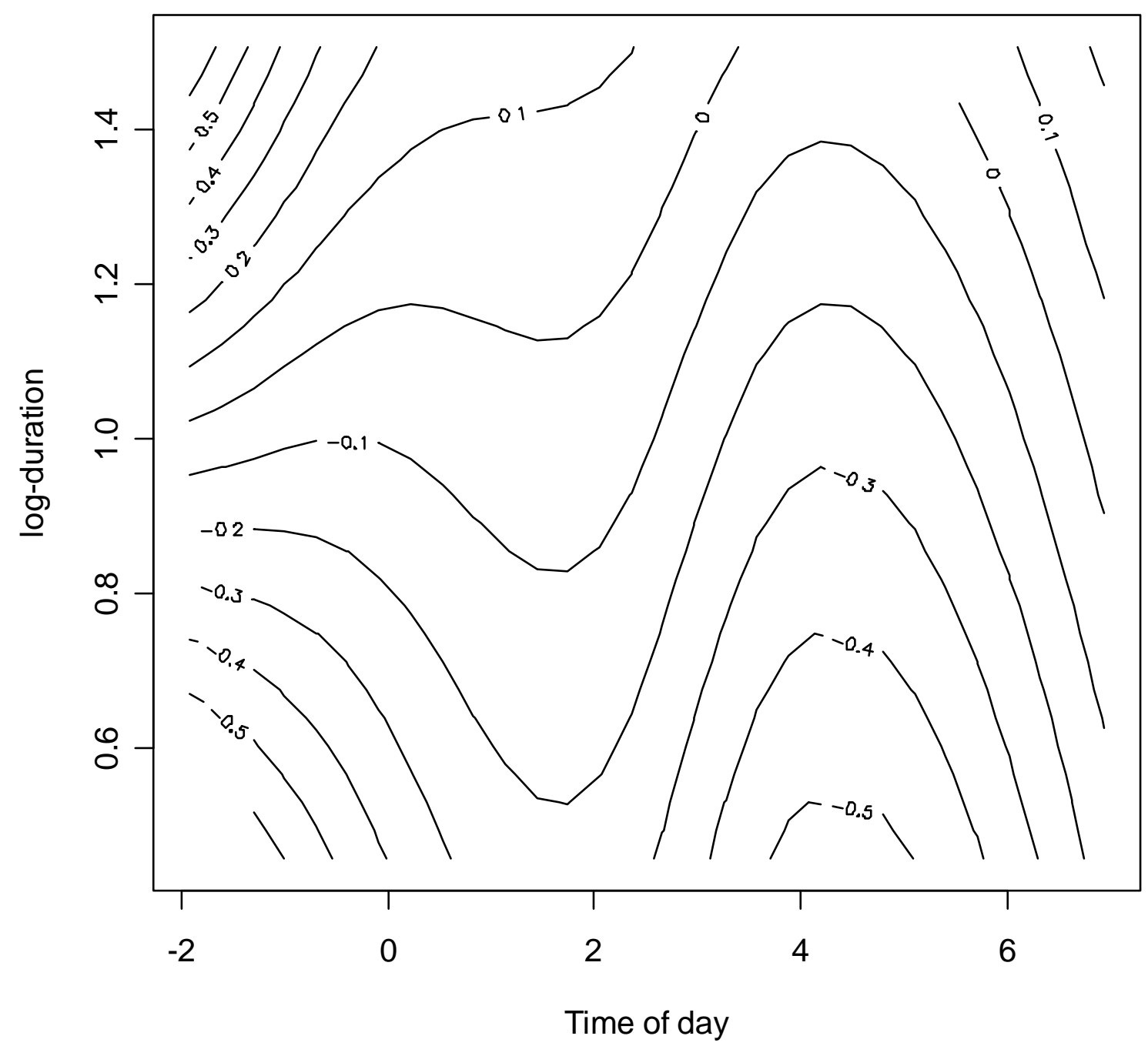

Fig. 5 Contour plot of estimated coefficients for haul log-duration and relative starting time in GAM model for Nephrops discard rates by Nephrops trawlers in the Bay of Biscay (July at $100 \mathrm{~m})$. 